\title{
El Plutón sintectónico ordovícico El León, extremo suroccidental del Cordón de Lila, región de Antofagasta, Chile
}

\author{
José Luis Carrasco ${ }^{1}, *$ Hans Niemeyer ${ }^{1}$ \\ ${ }^{1}$ Departamento de Ciencias Geológicas, Universidad Católica del Norte, Angamos 0610, Antofagasta, Chile. \\ j.carrasco.cortes@gmail.com,hansniemeyer.r@gmail.com \\ * Autor para correspondencia: hansniemeyer.r@gmail.com
}

\begin{abstract}
RESUMEN. El Plutón El León, ubicado en el Cordón de Lila, en la precordillera de la región de Antofagasta, Chile, es un cuerpo intrusivo que es parte del arco magmático famatiniano, en el borde suroccidental de Gondwana durante el Darriwiliano (Ordovícico medio). Presenta una marcada foliación magmática, se emplazó en la mesozona y se caracteriza por su composición granodiorítica, por tener grano grueso en su parte central y fino hacia los bordes y por alojar franjas concordantes métricas a decamétricas de rocas miloníticas. Adicionalmente, desarrolla una aureola metamórfica de contacto en su roca de caja. En este estudio se recolectaron cerca de 400 datos estructurales de la foliación magmática y milonítica en el plutón. La tendencia general de la foliación magmática es N77E junto con los indicadores cinemáticos S-C y con las micas con forma de pez de las milonitas indican que el movimiento de cizalle de estas fue de carácter normal-sinistral. Mediante el estudio de las microestructuras y evidencias petrográficas se identificó una continuidad de la deformación, desde el estado magmático, submagmático y de deformación en estado sólido de alta temperatura, hasta deformación sólida de baja temperatura. Durante su emplazamiento ocurrió un importante stoping magmático. Por otro lado, el desarrollo de milonitas al interior del plutón, con una deformación sólida de alta temperatura, sumado al carácter sinmagmático de la deformación y un componente vertical en el movimiento de cizalle son características que se ajustan a un modelo de emplazamiento del tipo pistón descendente para el Plutón El León. Su deformación marcaría la Fase tectónica compresiva Guandacol en el Cordón de Lila.
\end{abstract}

Palabras clave: Deformación magmática, Submagmática y en estado sólido, Fase tectónica Guandacol.

\begin{abstract}
The Ordovician syntectonic pluton El León, southwestern end of the Cordón de Lila, Antofagasta Region, Chile. The El León pluton, located in the Cordón de Lila in the Precordillera of the Antofagasta region, Chile, is an intrusive body emplaced in the famatinian magmatic arc in the southwestern margin of Gondwana during the Darriwilian (Middle Ordovician). It has a strong magmatic foliation and it is has a granodioritic composition that is coarse grained in its central part and fine grained in its borders. It contains metric and decametric fringes of mylonitic rocks. Aditionally it develops a contact metamorphic aureole in its country rock and it was intruded in the mesozone. There was collected $c a .400$ structural data from magmatic and mylonitic foliations inside the pluton. There was established that the general trend of the magmatic foliation is N77E and the shear sense from S-C foliations and mica-fish in the mylonites is normal-sinistral. By means of the analysis of microstructures and their associated deformation mechanisms it has established a continuous deformation sequence that started with magmatic deformation followed by submagmatic and solid-state deformations. The latter begun at high temperatures and was followed by low temperatures. An important magmatic stoping occurred during the plutonic emplacement. Besides, the development of high temperature mylonites, the sinmagmatic character of the deformation and a shear subvertical-sinistral component is compatible with a descending piston mechanism model. Its deformation is asigned to the compressive Guandacol tectonic phase in the Cordón de Lila.
\end{abstract}




\section{Introducción}

Los plutones ordovícicos del Cordón de Lila (Fig. 1) se emplazaron en un ambiente de arco magmático continental famatiniano en el borde suroccidental de Gondwana durante el Ordovícico (Zimmermann et al., 2010; Niemeyer, 2020a). La mayoría de ellos son post-tectónicos (Valencia, 2014). El Plutón El León es el más joven (Ordovícico Medio: Darriwiliano) y, a diferencia de los demás, posee una marcada foliación magmática, así como también franjas de milonitas que son paralelas a dicha foliación. Tales rasgos estructurales reflejan una dinámica especial en su emplazamiento, distinta de los demás plutones ordovícicos del Cordón de Lila, los cuales son isótropos y no presentan foliación magmática ni milonitas.
El presente trabajo intenta resolver los mecanismos de emplazamiento del Plutón El León, sobre la base de mediciones y mapeo de sus foliaciones y lineaciones tanto magmáticas como miloníticas, así como también del mapeo de la foliación metamórfica inducida en su roca de caja. A su vez, se busca establecer la historia de enfriamiento y deformación, según observaciones de la fábrica de las milonitas al microscopio (Fazio et al., 2020).

La relevancia de este estudio, en el contexto de la evolución geodinámica del borde suroccidental de Gondwana, es que proporciona información crucial sobre la deformación asociada a una fase tectónica compresiva ocurrida durante el Ordovícico medio, denominada Fase tectónica Guandacol (Salfity et al., 1984), contemporánea con el emplazamiento del Plutón El León.

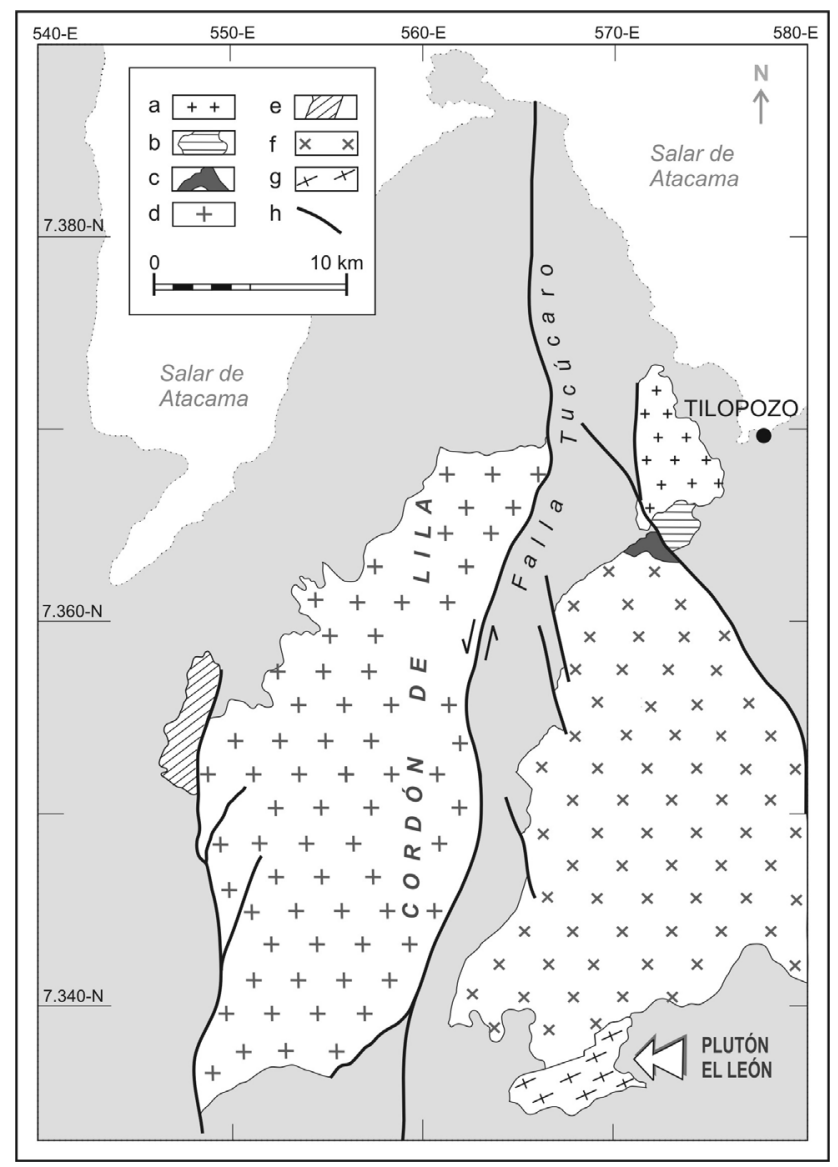

FIG. 1. Ubicación del Cordón de Lila y cuerpos intrusivos ordovícicos. a. Plutón Tucúcaro: monzogranito (476,8土3,7 Ma); b. Plutón

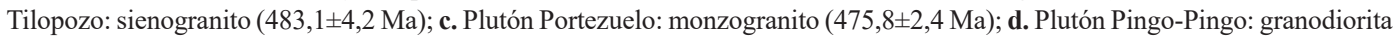

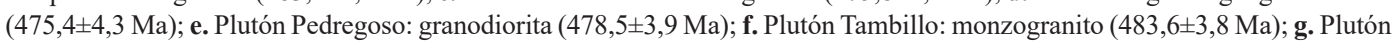

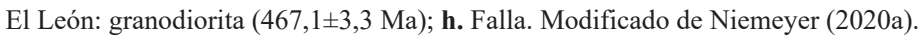




\section{Metodología}

El trabajo de campo incluyó la cartografía de los plutones El León y Guanaco: se midieron las foliaciones y lineaciones magmáticas en el primero y las foliaciones metamórficas en el segundo. En el Plutón El León se mapearon, además, cuerpos de milonitas y se determinó su foliación. Durante el levantamiento cartográfico se recolectaron 6 muestras de la foliación magmática y 15 de las milonitas del Plutón El León, las que fueron estudiadas en cortes pulidos y en cortes transparentes orientados a través de microscopía estándar. Para la determinación de las texturas de deformación en estas últimas se utilizó un microscopio petrográfico disponible en el Departamento de Ciencias Geológicas de la Universidad Católica del Norte. Se determinó indirectamente la edad de la foliación metamórfica del Plutón Guanaco, por medio de la datación en el borde metamórfico de 9 granos de circón por
LA-ICP-MS contenidos en la muestra de Basamento CHU-HN07/12, que fue enviada para datación al Laboratorio de Geocronología de la Universidad de Tasmania, Australia.

\section{Resultados}

\subsection{Características del Plutón El León y de su roca de caja}

El Plutón El León, de composición granodiorítica y color gris claro, aflora con una forma tabular, alargada en dirección NE-SO de aproximadamente $6 \mathrm{~km}$ de longitud por $1,8 \mathrm{~km}$ de ancho (Fig. 2). Es el plutón ordovícico más joven del Cordón de Lila

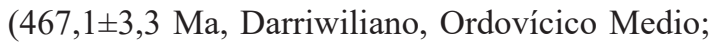
Niemeyer et al., 2014) y presenta dos asociaciones texturales en una misma composición petrográfica de granodiorita: una interna de grano grueso y otra de borde, externa (Fig. 2), de grano fino a medio, que se

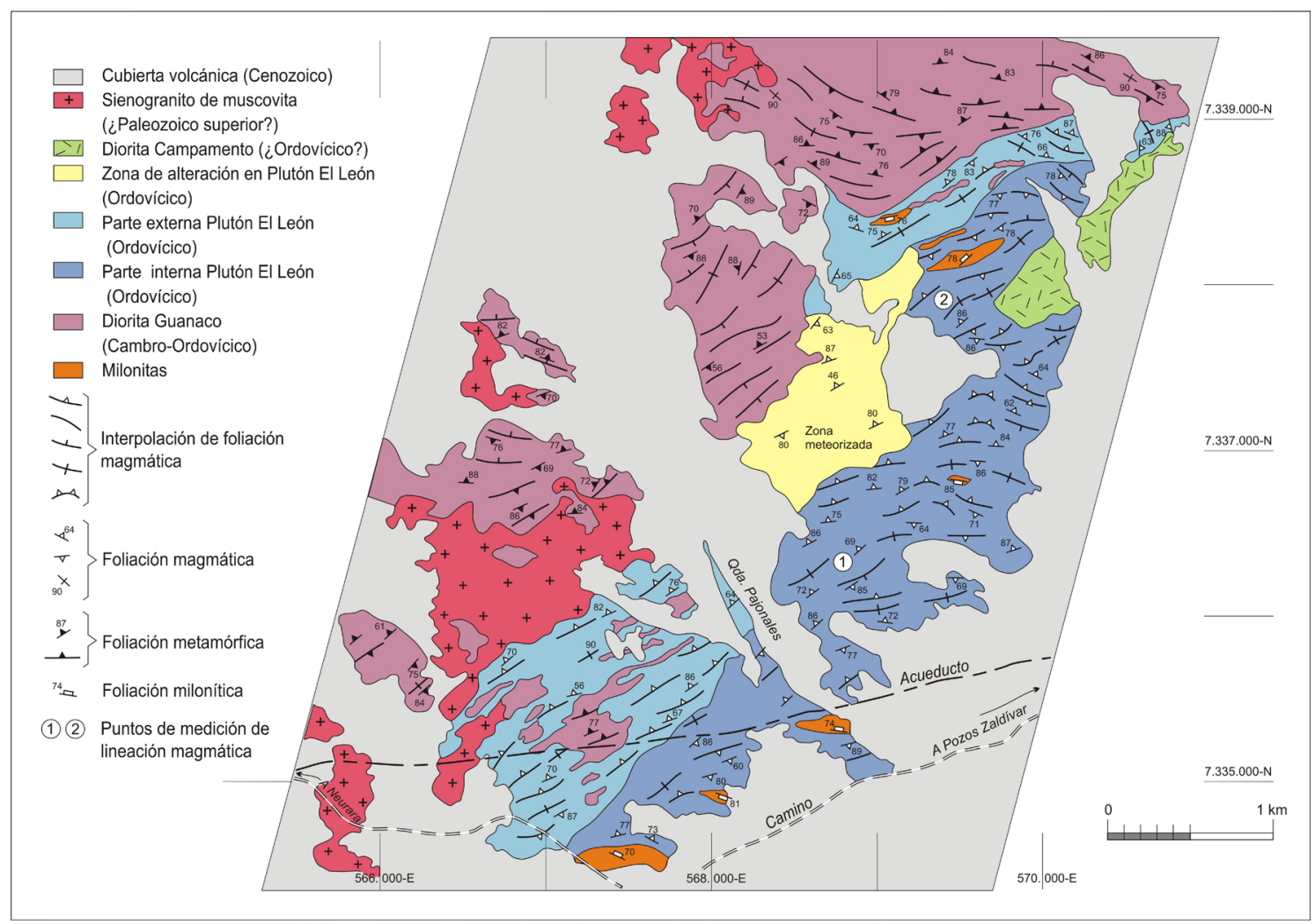

FIG. 2. Mapa geológico del Plutón El León y su roca de caja o Plutón Guanaco. Se observa el paralelismo entre la foliación magmática del Plutón El León y la foliación metamórfica inducida por este en su roca de caja. 
asocia al enfriamiento en el contacto con la roca de caja. Su rasgo estructural más característico es una marcada foliación magmática, que se distribuye en forma selectiva y que está definida por la orientación subparalela de sus cristales de plagioclasa y biotita, a lo largo y ancho de toda su extensión. Esta foliación es, a su vez, paralela con las franjas miloníticas, que se intercalan tanto en su borde como al interior del plutón (Fig. 2).

La roca de caja es una diorita de grano fino (Diorita Guanaco, de edad cambro-ordovícica: 490-475 Ma; Pankhurst et al., 2016), de color gris verdoso oscuro, en la que se desarrolla una foliación metamórfica paralela al contacto intrusivo del Plutón El León (Fig. 2) y aloja inclusiones de rocas metamórficas pertenecientes a un Basamento del Mesoproterozoico (Niemeyer, 2020b). Cercanamente al contacto lateral, en el sector noroccidental, y a su techo, en el sector suroccidental, se observan en la granodiorita del Plutón El León, numerosos xenolitos y roof-pendants alargados pertenecientes a la Diorita Guanaco (Fig. 2).

\subsubsection{Parte interna}

La parte interna del Plutón El León consiste en una granodiorita (Fig. 3) de grano grueso inequigranular, compuesta por un promedio de $44 \%$ de plagioclasa, $36 \%$ de cuarzo, $10 \%$ de feldespato potásico, $9 \%$ de biotita y $1 \%$ de minerales opacos. La plagioclasa es tabular subhedral a anhedral y presenta orientación paralela, en la que los cristales han rotado (Nicolas, 1992), lo que le otorga una marcada foliación magmática. En ella también se observan maclas polisintéticas, además de algunas maclas de Carlsbad-Albita y en ciertos cristales se observan otras con deflexión o se encuentran truncadas. El tamaño de los cristales es de 2-10 mm. El cuarzo está presente como agregados anhedrales intersticiales entre los cristales de plagioclasa y su tamaño es de 1-7 mm. El feldespato alcalino tiene cristales anhedrales de $1 \mathrm{~mm}$, intersticiales respecto de los cristales de plagioclasa y cuarzo. El más abundante es la microclina, pero también se observan algunos cristales de ortoclasa. La biotita es subhedral a anhedral con bordes rectos $\mathrm{y}$, en algunos casos, irregulares. El tamaño de los cristales es de 0,5-10 mm, con una media de $5 \mathrm{~mm}$. Como minerales accesorios se observa esfeno, circón, allanita y minerales opacos.

\subsubsection{Parte externa}

La parte externa corresponde a una granodiorita de grano fino a medio con foliación magmática y constituye una porción de borde y de techo del

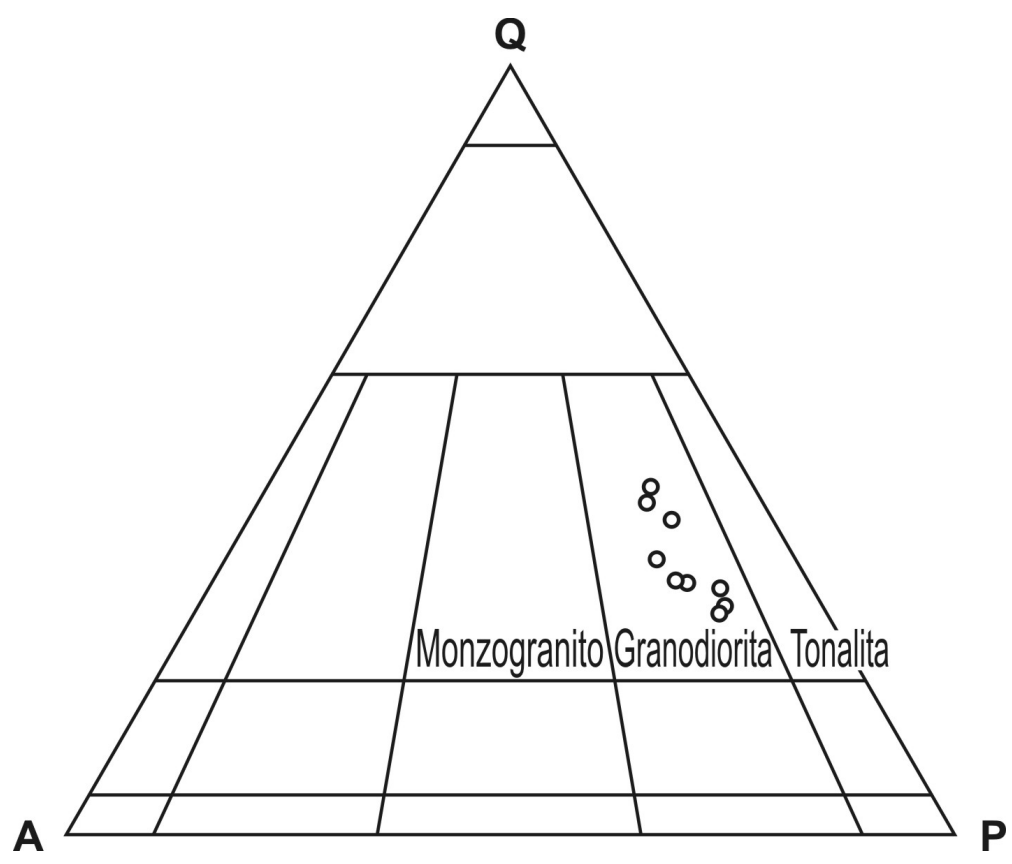

FIG. 3. Composición modal del Plutón El León en el diagrama QAP de Streckeisen (1974). Q: cuarzo; A: feldespato alcalino; P: plagioclasa. 
Plutón El León. El tamaño de grano se asocia al enfriamiento en el contacto con la roca de caja. Está compuesta por $45 \%$ de cristales tabulares subhedrales de plagioclasa con un tamaño de 0,2-2,5 mm, 40\% de cuarzo subhedral, que se presenta intersticial respecto a los cristales de plagioclasa y con un tamaño de $0,2-3 \mathrm{~mm}, 8 \%$ de ortoclasa subhedral de tamaño $0,2-1,0 \mathrm{~mm}$ la que es intersticial respecto a la plagioclasa y el cuarzo y $6 \%$ de cristales subhedrales de biotita, con un tamaño de 0,1-2 mm. Además, se observa un $1 \%$ de minerales opacos.

\subsection{Xenolitos y roof-pendants}

Los xenolitos y roof-pendants presentes en el Plutón El León son de diorita oscura de grano fino, provenientes de la Diorita Guanaco y aumentan en cantidad en las cercanías del contacto con esta. En el sector suroccidental del área, la parte de grano fino muestra numerosos xenolitos y roof-pendants de la Diorita Guanaco, los cuales tienen formas alargadas y dimensiones decamétricas con aspect ratios de 10:1 (Arbaret et al., 2000), donde su eje mayor es subparalelo a la foliación magmática; lo anterior sugiere que la orientación de estos se produjo por el flujo del magma huésped (Fig. 4).
Los xenolitos y roof-pendants poseen una foliación metamórfica interna, que es subparalela a la foliación magmática del Plutón El León. Los bordes de ellos son transicionales, mediante un contacto difuso, debido a la asimilación de estos por la roca huésped. La edad de la foliación metamórfica de los xenolitos fue determinada en bordes de nueve circones contenidos en uno de ellos (CHU-HN07/12), interpretados como bordes de crecimiento metamórfico. La edad ponderada obtenida es de $453 \pm 13$ Ma a nivel de 2 sigma de error analítico.

\subsection{Estructuras magmáticas}

\subsubsection{Foliación magmática}

El Plutón El León, tanto en sus partes de grano grueso como en las de grano fino a medio, presenta una marcada foliación magmática definida principalmente por la orientación paralela de cristales de plagioclasa y biotita. A escala del afloramiento, esta foliación corresponde a franjas de biotita primaria que se distribuyen a través de toda la roca (Fig. 5) y los minerales que la constituyen no muestran rasgos de deformación intracristalina. Estas características indican que la fábrica puede ser considerada como una foliación de flujo magmático, ligada al movimiento

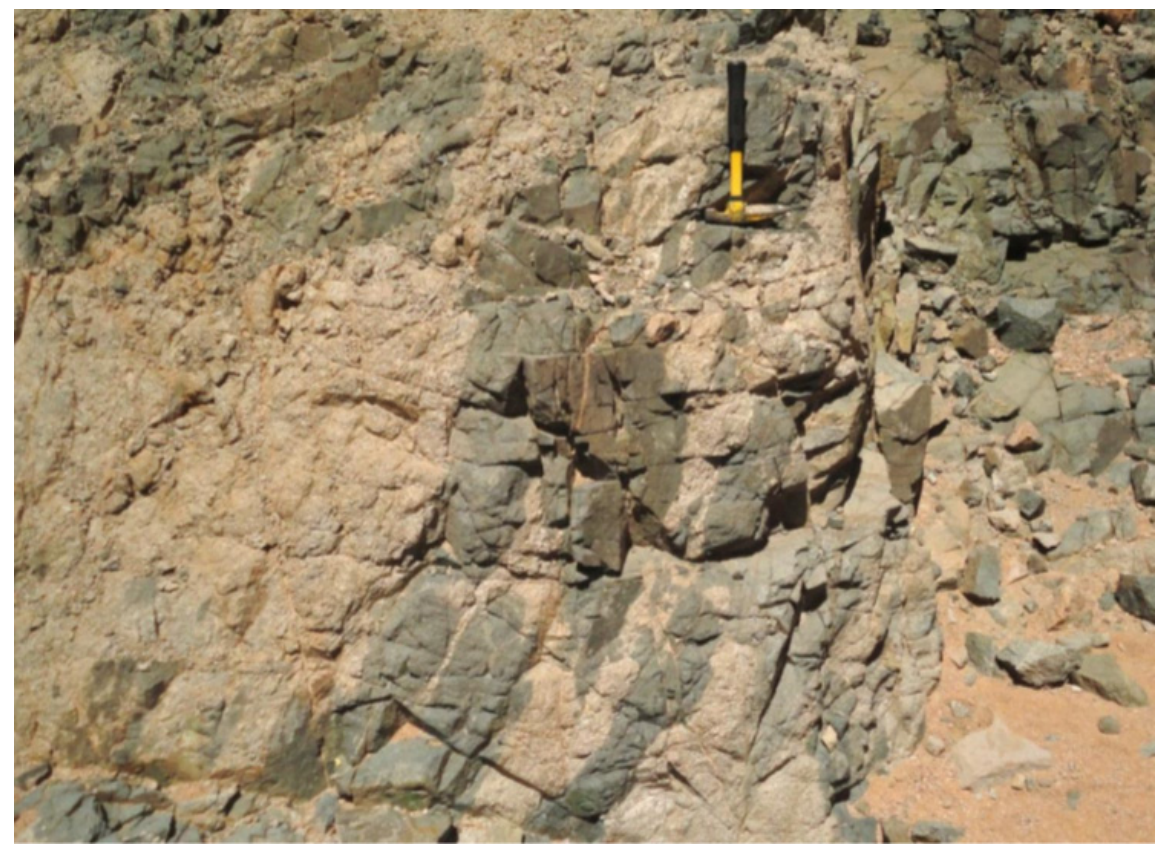

FIG. 4. Xenolitos de la Diorita Guanaco dentro de la facies de borde del Plutón El León. 


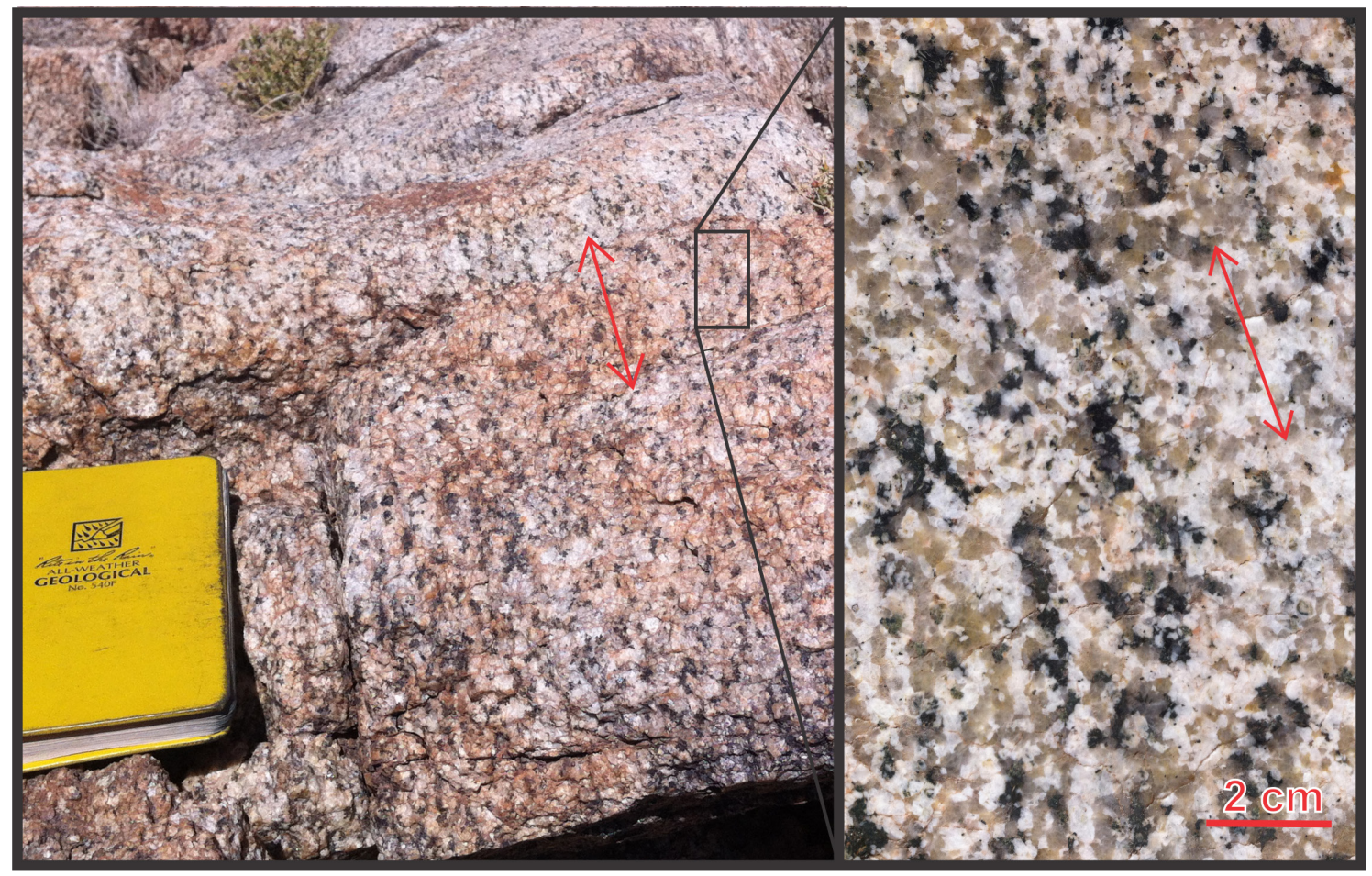

FIG. 5. Foliación magmática en el Plutón El León. En el lado izquierdo se muestra la foliación magmática en afloramiento; en el lado derecho, una sección pulida con el detalle de la orientación de los cristales de biotita y plagioclasa. La flecha roja indica la orientación de la foliación.

de la fase fluida de un cuerpo plutónico parcialmente cristalizado.

Se midieron en terreno 392 planos de foliación magmática, los cuales, en una proyección equiareal (Fig. 6A), arrojan una orientación dominante N77E/37NO.

En el sector septentrional del Plutón El León se observa que los polos de los planos de foliación $(n=144)$ se concentran en la orientación N79E/38NO (Fig. 6B), similar a la orientación general dominante. Los polos de foliaciones del sector central del Plutón El León ( $\mathrm{n}=149)$ muestran una concentración en los extremos noroeste y sureste de la proyección, es decir, más dispersa en los 4 cuadrantes, cambio que se debe a una inflexión dextral que sufre la foliación en el extremo norte de esta zona. En dicho sector los datos tienen una orientación dominante de los planos N77E/27NO, similar al caso anterior, pero con un manteo menor (Fig. 6C). Las foliaciones del sector meridional del Plutón El León $(n=99)$ también muestran una concentración de polos en los cuadrantes noroeste y sureste de la proyección, con una orientación media de N72E/54NO (Fig. 6D). Los planos de foliación magmática se comportan de manera similar en la zona central y meridional con solo cambios en el manteo. Sin embargo, en el norte, además de cambios de manteo, los hay en el rumbo de los planos.

\subsubsection{Lineación magmática}

En el Plutón El León, las lineaciones magmáticas se expresan macroscópicamente por la orientación preferencial lineal de agregados cristalinos de plagioclasa y biotita, los que conforman una recta contenida en el plano de foliación magmática, es decir, constituyen una fábrica plano-lineal S-L. En terreno se midió el rake o barrido de la lineación respecto a la línea de rumbo del plano de la foliación. La lineación magmática fue medida en dos estaciones de trabajo, y en cada una de ellas se tomaron 32 y 31 datos.

En la estación 1, esta lineación revela un buzamiento preferente hacia el noroeste y cercano a la vertical, con una concentración máxima en la dirección N20O/79NO (Fig. 7A). En la estación 2, a diferencia 


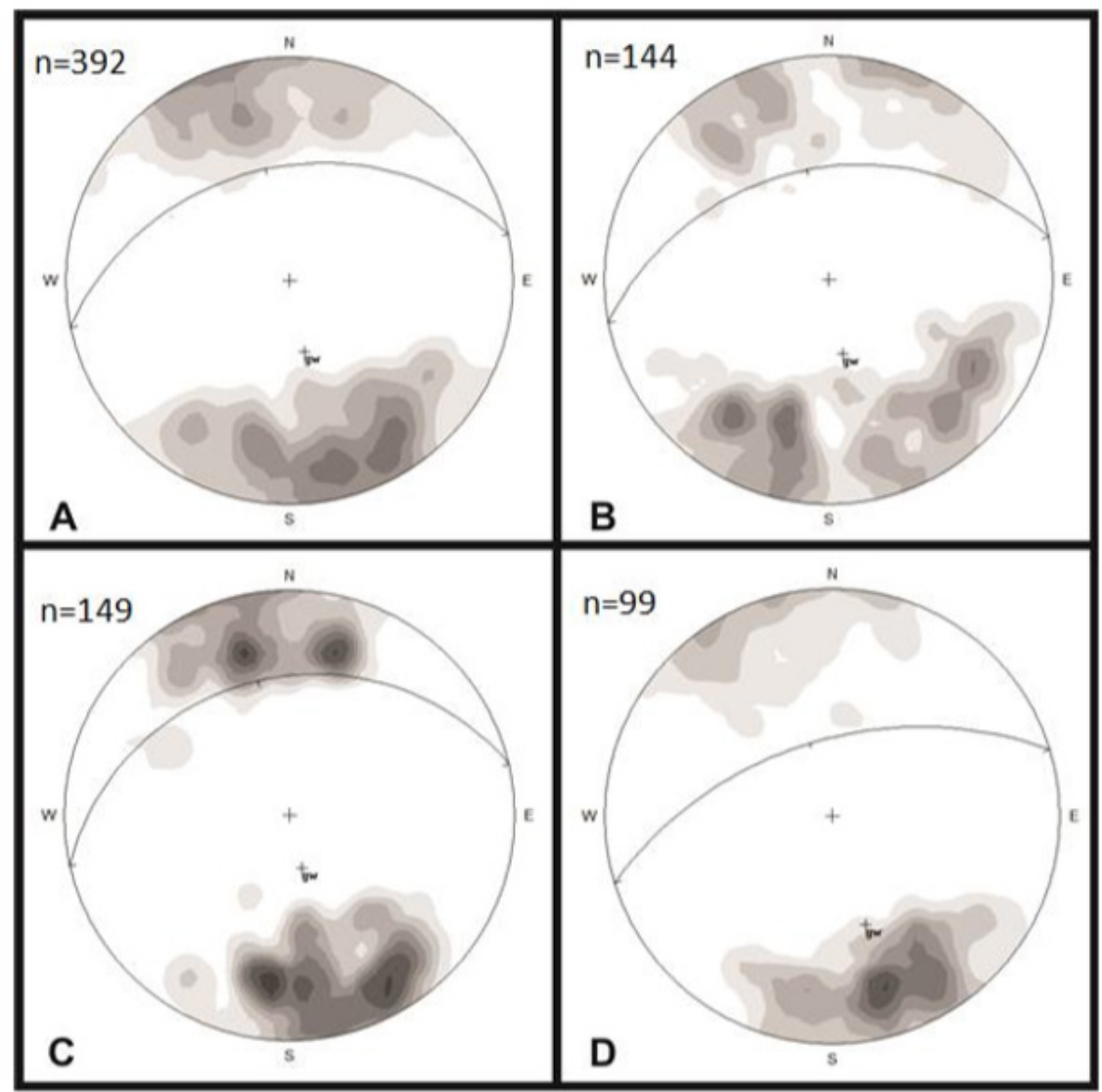

FIG. 6. Proyección equiareal de polos de planos de foliación magmática en el Plutón El León. A. Todos los datos; B. Sector septentrional; C. Sector central; D. Sector meridional. Además, se muestra el plano representativo de la concentración máxima de datos con su respectivo polo $(\mathrm{gw}), \mathbf{n}$ : número de mediciones.

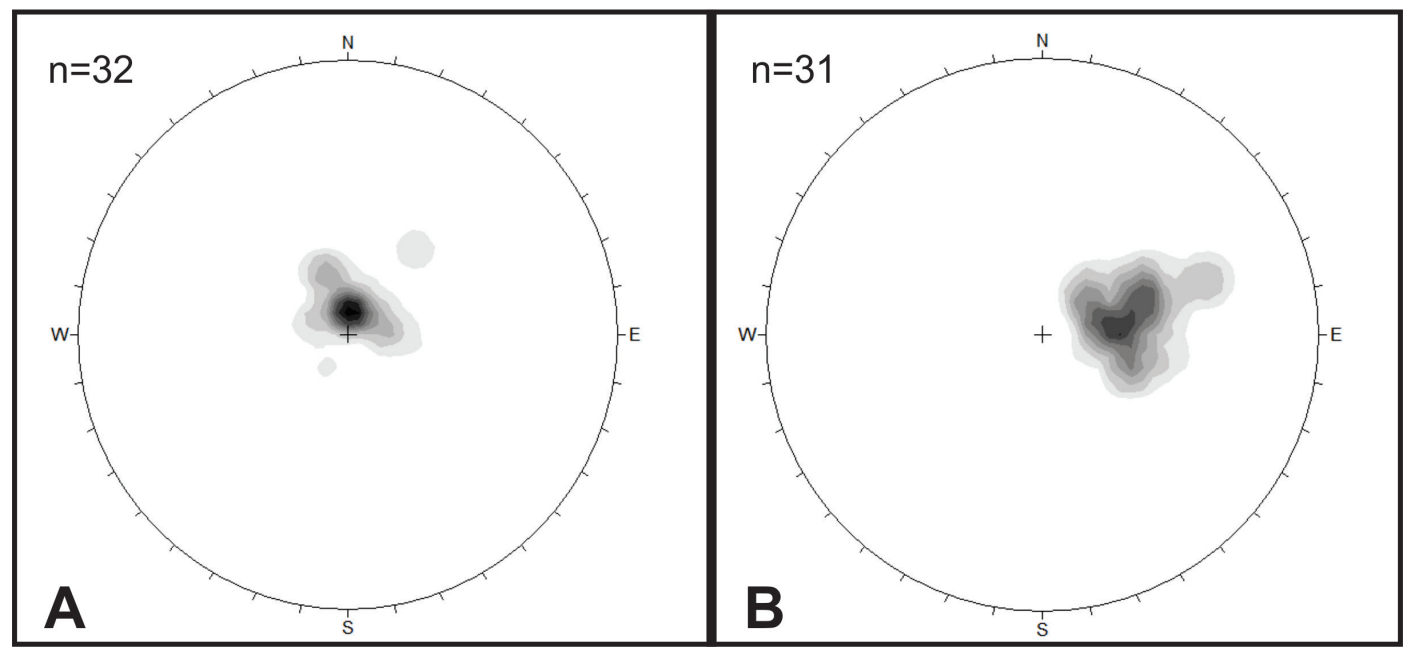

FIG. 7. Proyección equiareal de lineación magmática en el Plutón El León. A. Lineación correspondiente a la estación de medida 1. B. Lineación correspondiente a la estación de medida 2. n: número de mediciones. 
de la anterior, la lineación presenta un buzamiento preferencial hacia el noreste, con una concentración máxima en la dirección N79E/55NE (Fig. 7B). La rotación dextral de la lineación en la estación 2 respecto de la estación 1 se debe a la inflexión en el mismo sentido de la foliación magmática.

\subsection{Las franjas de milonitas}

En el Plutón El León se observan varias franjas de milonitas que se distribuyen en sus bordes, $\mathrm{y}$ en la parte interna del Plutón (Fig. 8). En ellas se estudiaron indicadores cinemáticos macroscópicos y microscópicos, además de lineaciones.

\subsubsection{Indicadores cinemáticos macroscópicos}

En las muestras de milonitas se realizaron cortes perpendiculares a la foliación y paralelos a la lineación, en cuyas secciones se identificaron indicadores cinemáticos de tipo S-C y sigma, que indican un movimiento de cizalle normal-sinistral (Fig. 9). En una muestra se observó un arreglo de cristales de biotita con forma de pez (micas fish), compatible con un movimiento normal-sinistral.

\subsubsection{Indicadores cinemáticos microscópicos}

Aunque macroscópicamente los cristales de biotita tienen forma de pez, al microscopio se observó que no corresponden a un mineral individual deformado, sino que son un arreglo de varios cristales de bordes poligonales. Se realizó un análisis estadístico mediante platina universal, el que tomó como parámetro la orientación del plano de los cristales de biotita. Ella se representa en la figura 10, donde se aprecia una orientación preferencial de los planos $\mathrm{C}$ y una secundaria de los planos $\mathrm{S}$, resultado que indica un movimiento de cizalle normal-sinistral, al igual que los indicadores cinemáticos macroscópicos.

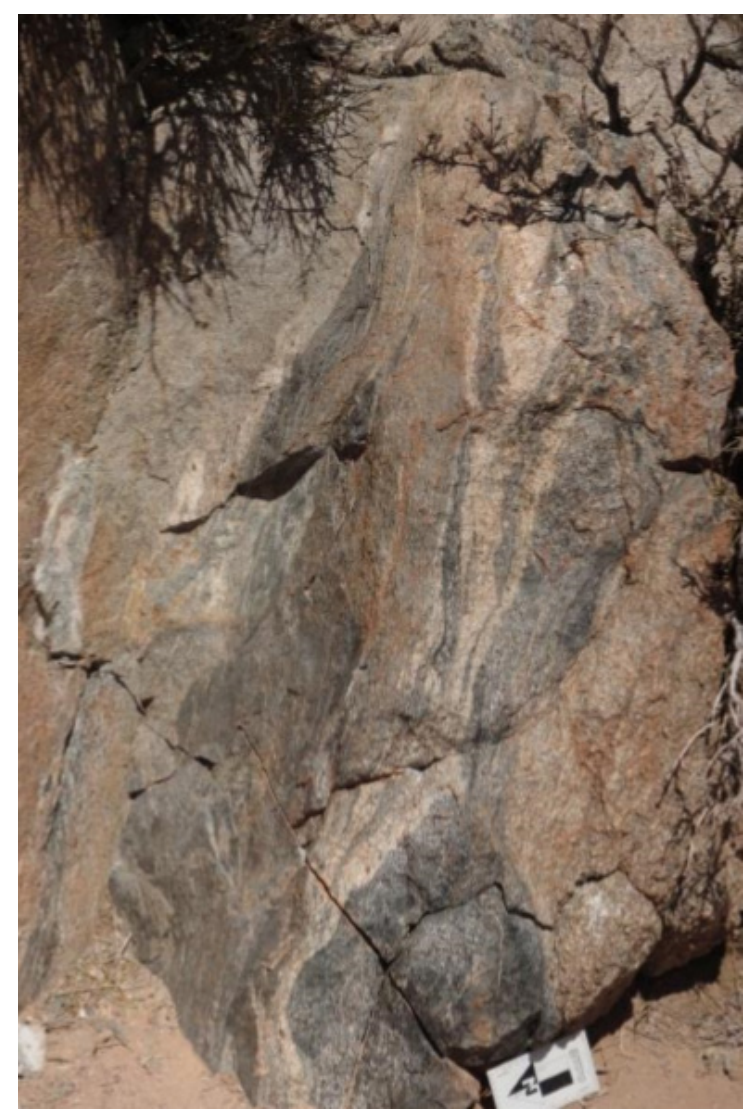

FIG. 8. Ejemplo de franja de milonitas en el sector central del Plutón El León. Se evidencia la segregación de bandas leucocráticas y melanocráticas. 


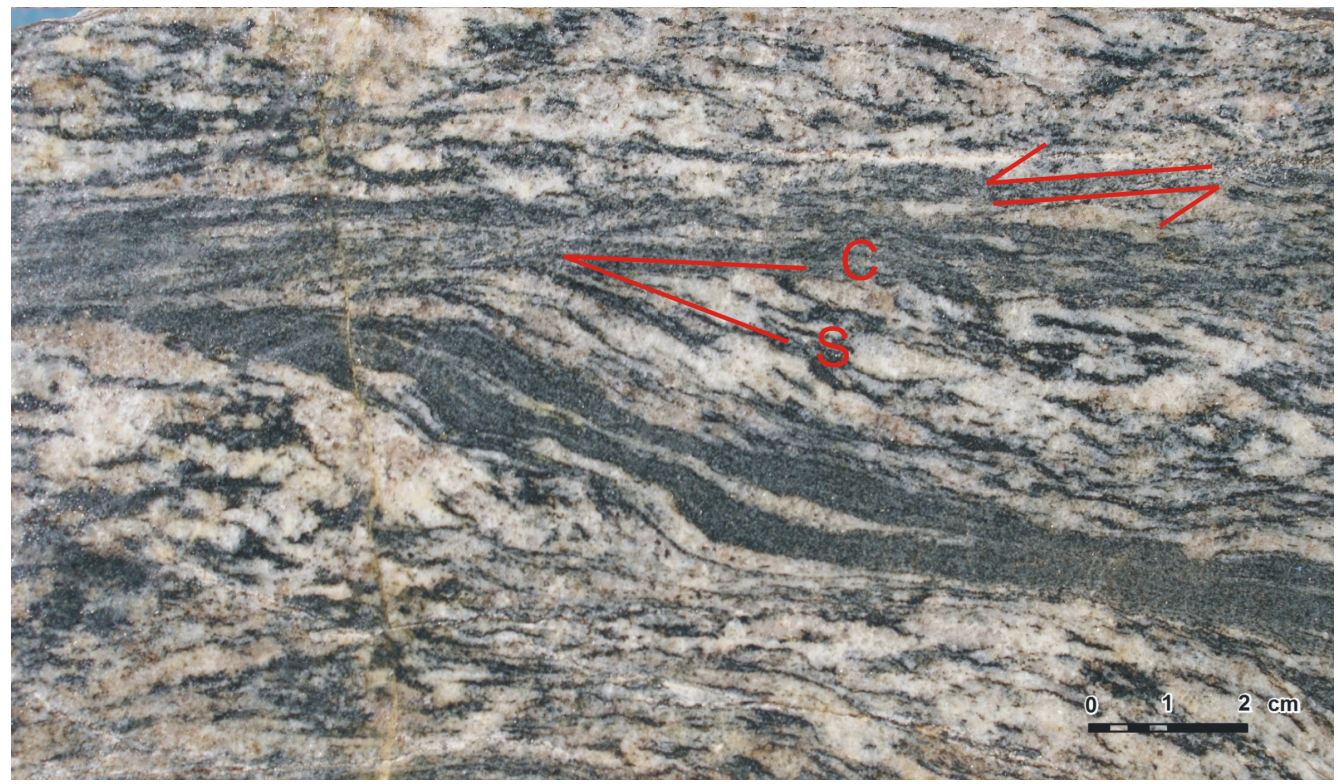

FIG. 9. Indicador cinemático S-C en milonita. Corte en el plano XZ del elipsoide de strain. Las flechas indican movimiento de cizalle sinistral.

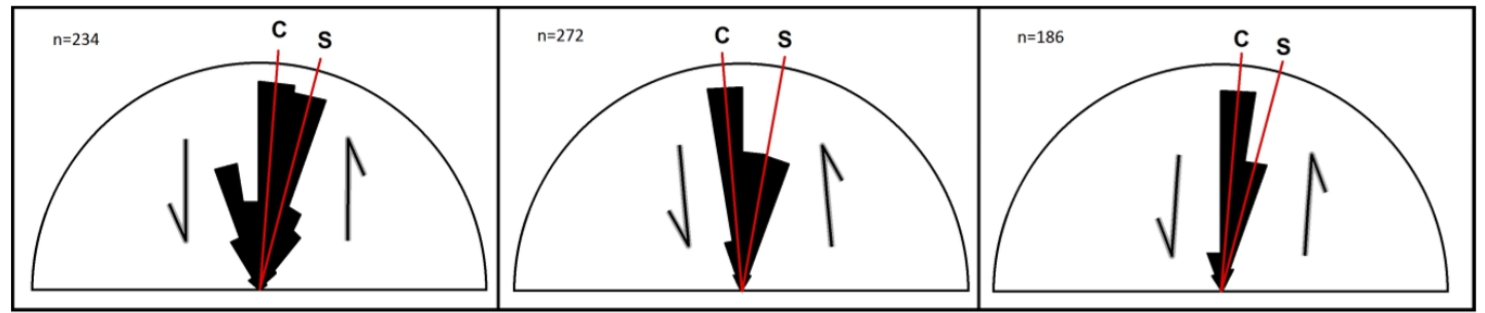

FIG. 10. Análisis estadístico de orientación de cristales de biotita. Se indican los planos S y C, n: número de mediciones. Las flechas indican el sentido de movimiento de cizalle normal-sinistral.

\subsubsection{Lineaciones miloníticas}

En las zonas miloníticas dentro del Plutón el León se observan lineaciones con un buzamiento preferente hacia el noreste y hacia el este. En la figura 11 se muestran las lineaciones miloníticas en comparación con las lineaciones magmáticas de la estación 2. El vector promedio para las lineaciones miloníticas es igual que las lineaciones magmáticas de la estación 2 y tiene una orientación N78E/55NE.

\subsection{Microestructuras y mecanismos de deformación}

Con el fin de caracterizar los mecanismos de deformación que afectaron tanto a las rocas del Plutón El León como a sus franjas miloníticas, se realizó una descripción y análisis de su microfábrica. Se puso especial énfasis en identificar la morfología de los bordes de los cristales, y la presencia de subgranos y maclas de deformación, además del tipo de extinción que presentan los distintos minerales. Estos parámetros, en conjunto, entregan información acerca de la temperatura y el tipo de recristalización a los cuales se sometieron los minerales durante la deformación dúctil (Passchier y Trouw, 2005).

\subsection{Deformación magmática}

La fábrica magmática corresponde a la foliación magmática del Plutón El León, dada por la orientación subparalela de cristales de plagioclasa y biotita, 


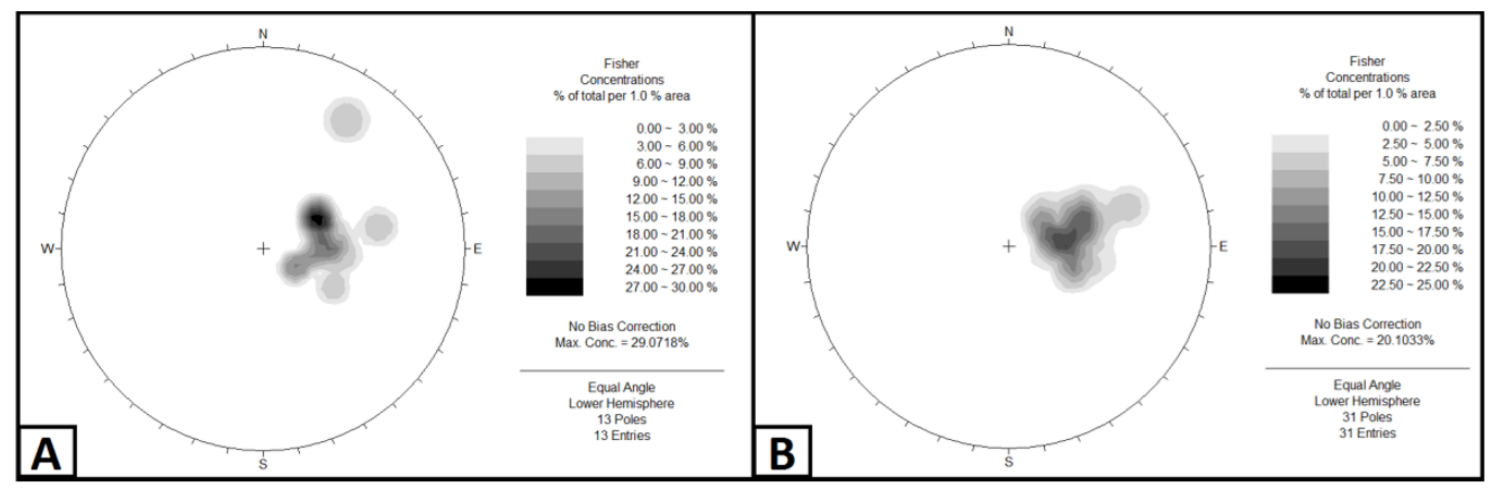

FIG. 11. Lineaciones. A. Lineaciones miloníticas; B. Lineaciones magmáticas en la estación de medida 2.

originada por flujo del magma, en que los cristales también habrían rotado, sin que haya habido suficiente interacción entre ellos como para que experimenten una deformación plástica (Blenkinsop, 2002).

\subsection{Deformación submagmática}

A medida que el magma se enfría, aumenta el porcentaje de cristales con una consecuente disminución de la fase fundida. Cuando esta llega a un 30-35\%, se alcanza la fracción de fase fundida crítica (the critical melt fraction), que es equivalente a cuando el magma deja de tener un comportamiento newtoniano ideal, donde los cristales ya formados en él interactúan entre sí, y producen deformación plástica submagmática y también rígida por choques (Fazio et al., 2020).

Al microscopio, el evento de deformación submagmática se manifiesta, en el Plutón El León, al interior de algunos cristales de cuarzo que tienen un tipo especial de extinción llamada de tablero de ajedrez (chessboard extinction; Kruhl, 1996), (Fig. 12A). Este tipo de extinción indica que hubo un deslizamiento simultáneo de los planos prismático [c] y basal $<\mathrm{a}>$, lo que solamente ocurre a altas temperaturas de deformación (Blumenfeld et al., 1986).

\subsection{Deformación sólida}

Es un tipo de deformación donde los cristales pueden deformarse internamente sin fracturarse, debido al movimiento de los defectos reticulares (lattice defects). En este caso, una modificación permanente en la forma de un cristal solo es posible por un cambio en las posiciones relativas de los átomos que lo conforman (Poirier, 1985; Jessell, 1987). En las franjas miloníticas dentro del Plutón El León se han identificado texturalmente dos episodios de deformación sólida: uno de alta temperatura y otro de baja temperatura $\left(<500^{\circ} \mathrm{C}\right)$.

\subsubsection{Deformación sólida de alta temperatura}

Este episodio se caracteriza principalmente, por presentar cristales con bordes bien lobulados (Fig. 12B y C), donde el mecanismo de deformación que produce estos bordes es la recristalización por migración de bordes de granos (grain boundary migration), (Hirth y Tullis,1992; Stipp et al., 2002). A alta temperatura, la recristalización por migración de bordes de granos provoca movilidad de los bordes de los cristales, lo cual da como resultado la remoción de dislocaciones y subgranos. Esto origina cristales con bordes bien lobulados y con una apariencia libre de deformación, es decir, no hay subgranos y los cristales no presentan extinción ondulosa (Passchier y Trouw, 2005).

En algunos cristales de feldespato potásico del Plutón El León se observó un tipo especial de pertitas, producidas durante la deformación sólida de alta temperatura, que son llamadas flame-perthite (Fig. 12D), las que se orientan paralelamente a los planos de cizalle C (Pryer et al., 1995).

La recuperación (recovery) es un término que se utiliza para referirse a todos los mecanismos que contribuyen a reducir la densidad de dislocaciones en los cristales deformados (Passchier y Trouw, 2005). Por lo tanto, esta elimina los subgranos y la extinción ondulosa.

La observación de cristales con bordes bien lobulados sugiere que la temperatura de la deformación 
sólida ocurrió entre 500 y $700{ }^{\circ} \mathrm{C}$ (Jessell, 1987) y las flame-perthite indican condiciones de temperatura mayores a $600{ }^{\circ} \mathrm{C}$ (Altenberger y Wilhelm, 2000). A estas temperaturas, la recristalización y la recuperación se producen con mayor facilidad y rapidez, por lo que los cristales deberían presentar una apariencia libre de deformación (Blumenfeld et al., 1986). Sin embargo, los cristales con bordes lobulados del Plutón El León tienen extinción ondulosa y/o maclas de deformación, características que demostrarían una posterior deformación sólida de menor temperatura sobrepuesta a la deformación sólida de alta temperatura.

\subsubsection{Deformación sólida de baja temperatura}

La deformación sólida de baja temperatura se sobrepone a la de alta temperatura y se caracteriza por la presencia de extinción ondulosa en los cristales de cuarzo con bordes lobulados.

Los cristales de cuarzo que presentan bordes lobulados, producto de la recristalización por migración de bordes de granos (grain boundary migration), deberían tener un aspecto libre de deformación. Sin embargo, en el Plutón El León, presentan extinción ondulosa, lo que indica que una nueva deformación sólida de menor temperatura se sobrepuso a la anterior (Fig. 13A). También podría tratarse de una migración incompleta de bordes de grano.

Se observan, además, maclas de deformación irregulares y con terminaciones en forma de cuña, producidas durante la deformación de baja temperatura, en cristales de plagioclasa con bordes irregulares generados por la deformación de alta temperatura (Fig. 13B), lo que, de igual modo, evidencia la sobreposición de la deformación de baja temperatura. Por otro lado, se encuentran cristales levemente fracturados, lo que indica que estuvieron sometidos a esfuerzos en condiciones de baja temperatura.

En las muestras estudiadas se presentan abundantes subgranos en cristales de cuarzo y plagioclasa, los cuales son generados por el mecanismo de deformación llamado bulging (Stipp et al., 2002). Este proceso opera a baja temperatura, en condiciones según las cuales la movilidad de los bordes de los cristales es local, y en la que el borde del cristal forma un lóbulo dentro del cristal adyacente y genera un nuevo cristal independiente de menor tamaño (Fig. 13C).
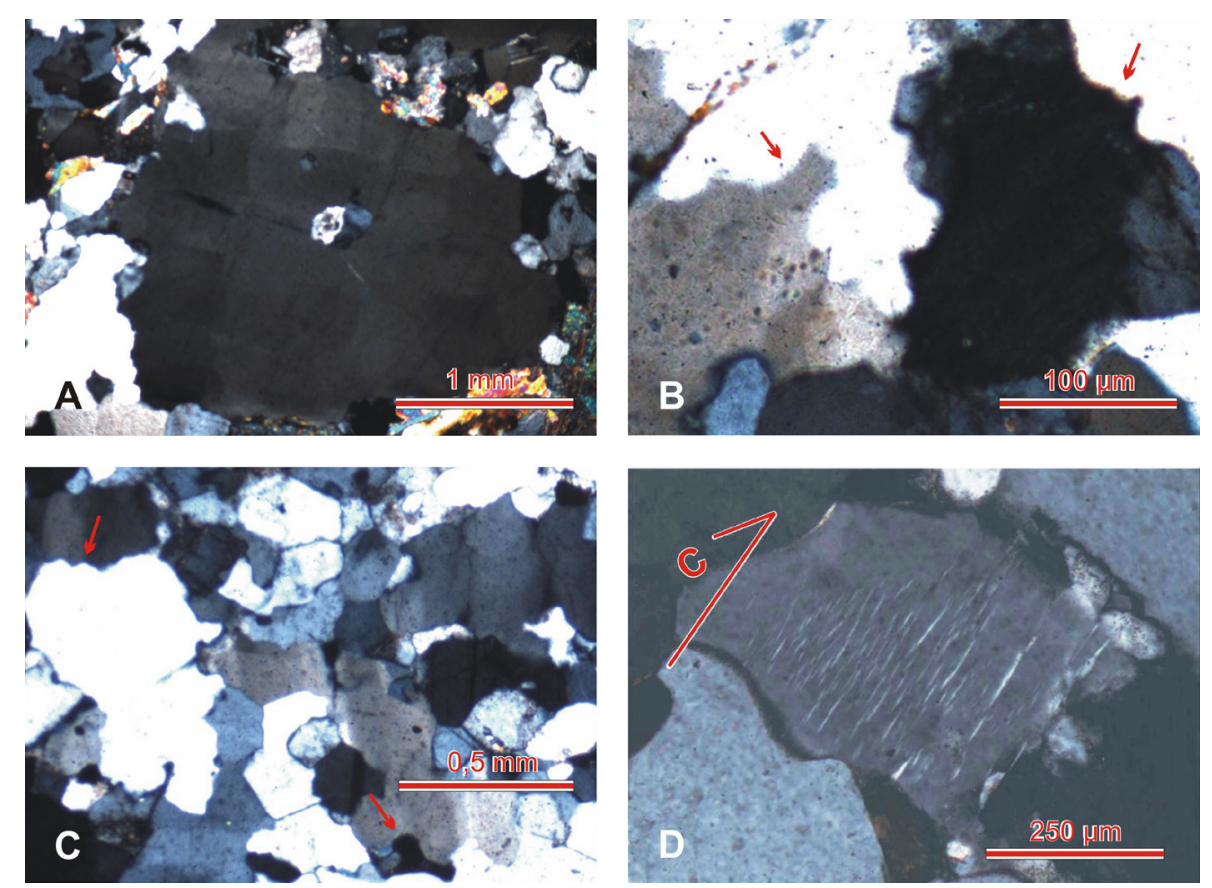

FIG. 12. Microfábrica de la deformación sólida de alta temperatura. A. Chessboard extinction en cristal de cuarzo; B. Cristales con bordes lobulados, que se muestran con las flechas; C. Extinción ondulosa en cristales de cuarzo con bordes lobulados; D. Flame-perthite en cristal de feldespato potásico; la flecha muestra la dirección de cizalle. 

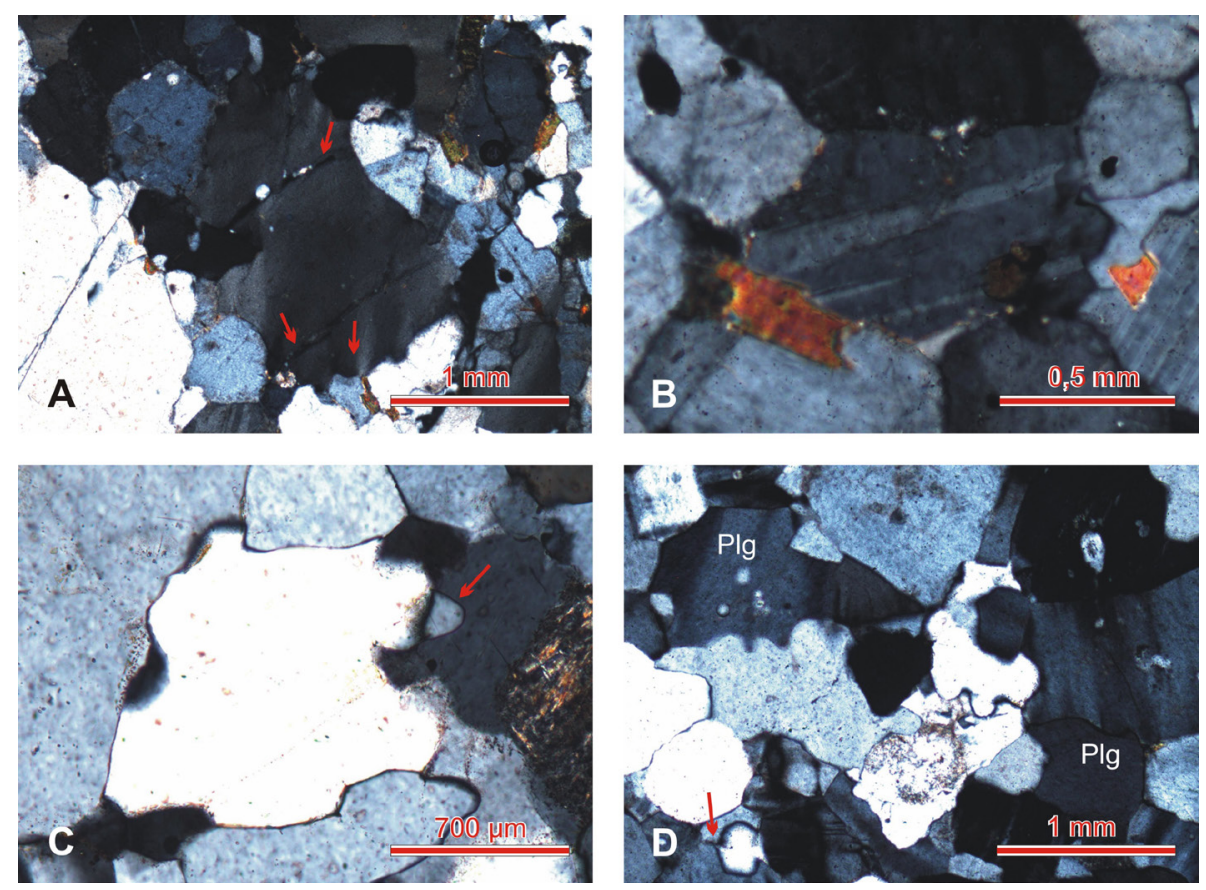

FIG. 13. Microfábrica de la deformación sólida de baja temperatura. A. Cristal de cuarzo de bordes lobulados con extinción ondulosa y fracturas; las flechas indican las fracturas y los bordes; B. Maclas de deformación irregulares y con terminación en cuña, en cristales de plagioclasa; C. Subgrano de cuarzo indicado por la flecha; D. Cristales de plagioclasa con bordes lobulados y extinción ondulosa; la flecha indica cristal de cuarzo fracturado.

Existen fracturas de poca magnitud en los cristales de plagioclasa y feldespato potásico, al igual que en algunos cristales de cuarzo (Fig. 13D), lo que indica que la temperatura a la cual se produjo la deformación sólida de baja temperatura en el Plutón El León fue superior a $300^{\circ} \mathrm{C}$, ya que bajo este valor el comportamiento del cuarzo es completamente frágil (Fazio et al., 2020).

\section{Discusión y conclusiones}

La mayoría de los plutones ordovícicos ( $c a$. 483$475 \mathrm{Ma}$ ) del Cordón de Lila son cuerpos intrusivos de carácter post-tectónico emplazados en la epizona (Valencia, 2014). La excepción está constituida por el Plutón El León (467 Ma), que es el único que presenta deformación sinmagmática, materializada por una foliación magmática paralela a su elongación en dirección NE (Fig. 2).

La existencia en el Plutón El León de un borde externo de granodiorita de grano fino a medio expuesta tanto en el flanco como en el techo y asociada al enfriamiento en el contacto con la roca de caja, así como también la estrecha zona de metamorfismo de contacto, unido a la exposición del techo del plutón, le confieren características de emplazamiento en la mesozona. Los numerosos xenolitos y roof-pendants de sus rocas de caja en su techo y borde indican que, durante el emplazamiento de esta unidad, ocurrió un importante mecanismo de stoping magmático (Zák et al., 2006).

Por otra parte, dado el paralelismo de los cuerpos de milonitas incluidos en el Plutón El León con la foliación magmática del mismo (Fig. 2), se las interpreta como que tuvieron un desarrollo simultáneo o ligeramente tardío respecto al emplazamiento de este a ca. $500{ }^{\circ} \mathrm{C}$ (Gapais, 1989; Paterson et al., 1989).

El comportamiento estructural de la foliación metamórfica, que presenta una disposición subparalela a la foliación magmática (Fig. 2), fue observado en la roca de caja de este plutón junto con la presencia al interior de él de xenolitos y roof-pendants foliados, lo que indica que durante su emplazamiento el Plutón El León fue afectado por una deformación regional compresiva (Paterson et al., 1998). La dirección del esfuerzo principal (NO-SE), responsable del proceso tectónico, se puede considerar como perpendicular 
tanto a la foliación magmática del Plutón El León como a la metamórfica (NE-SO) inducida por este en el Plutón Guanaco, al cual intruye. De acuerdo con los indicadores cinemáticos macroscópicos (Fig. 9) y microscópicos (Fig. 10) en las milonitas, el Plutón El León fue afectado durante su emplazamiento por un cizallamiento normal-sinistral. Este evento tectónico puede ser, temporalmente, relacionado con la Fase tectónica compresiva Guandacol (Salfity et al., 1984) que afectó a las rocas del arco magmático famatiniano (del que los plutones del Cordón de Lila forman parte) durante el Darriwiliano (467-468 Ma) (Niemeyer y Sanhueza, 2016). Cabe mencionar que la dirección de acortamiento (NO-SE) deducida aquí, no está de acuerdo con la elongación NO del arco magmático famatiniano. Según esto último, la dirección de acortamiento debería ser NE-SO y posiblemente haya sido rotada en el sentido del reloj, en relación con el movimiento sinistral de la Falla Tucúcaro (Fig. 1)(Michea, 2014).

Las evidencias petrográficas y texturales (Figs. 12 y 13) permiten inferir que el Plutón El León fue afectado por deformación magmática, submagmática y en estado sólido de alta y baja temperatura, lo que constituye probablemente un proceso continuo de deformación, desarrollado entre su edad de cristalización (467 $\pm 3 \mathrm{Ma}$ ) y la de la foliación de los xenolitos (453 $\pm 13 \mathrm{Ma}$ ). Además, una deformación sinmagmática es registrada por la foliación y lineación magmáticas observadas en el plutón (Figs. 5 y 8), en tanto que la deformación submagmática es evidenciada por la presencia de cuarzo con textura de extinción del tipo tablero de ajedrez (Fig. 12A). El proceso de deformación sólida de alta temperatura es revelado por la existencia de cristales de bordes lobulados, en particular de cuarzo (Fig. 12B) y la presencia de las denominadas flame perthites, procesos que ocurren a temperaturas sobre los $500{ }^{\circ} \mathrm{C}$ (Jessell, 1987; Altenberger y Wilhelm, 2000). La presencia de cuarzo con bordes lobulados afectados por extinción ondulosa y feldespatos con maclas con forma de cuña atestiguan el efecto de una deformación de baja temperatura ( $\mathrm{ca} .300-500{ }^{\circ} \mathrm{C}$ ) (Fazio et al., 2020) sobrepuesta a la de alta temperatura. Esta secuencia de deformación sugiere la posibilidad del desarrollo de un proceso continuo, que varía progresivamente desde el estado magmático a deformación en estado sólido de baja temperatura, que acompaña el enfriamiento y cristalización gradual del magma (Fig. 14), (Pennacchioni y Zucchi, 2013; Fazio et al., 2020).

Finalmente, el desarrollo de milonitas con una deformación sólida tanto de alta temperatura como de baja temperatura, sumado al carácter sinmagmático de la deformación y una componente con carácter normal-sinistral, además de la forma tabular del plutón, son características que se ajustan al modelo de emplazamiento plutónico de tipo pistón descendente propuesto por Cruden (1998). El movimiento de pistón habría estado activo durante la última etapa de cristalización del Plutón El León y la mayor parte del espacio para el emplazamiento de este se habría producido por descenso dúctil de su piso (Fig. 15).

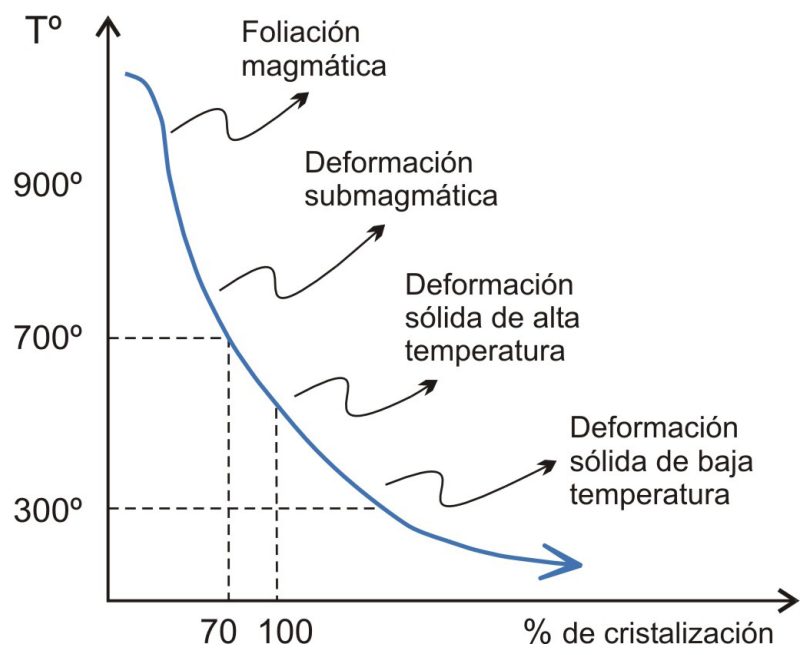

FIG. 14. Eventos de deformación continua que tuvieron lugar en el Plutón El León. 


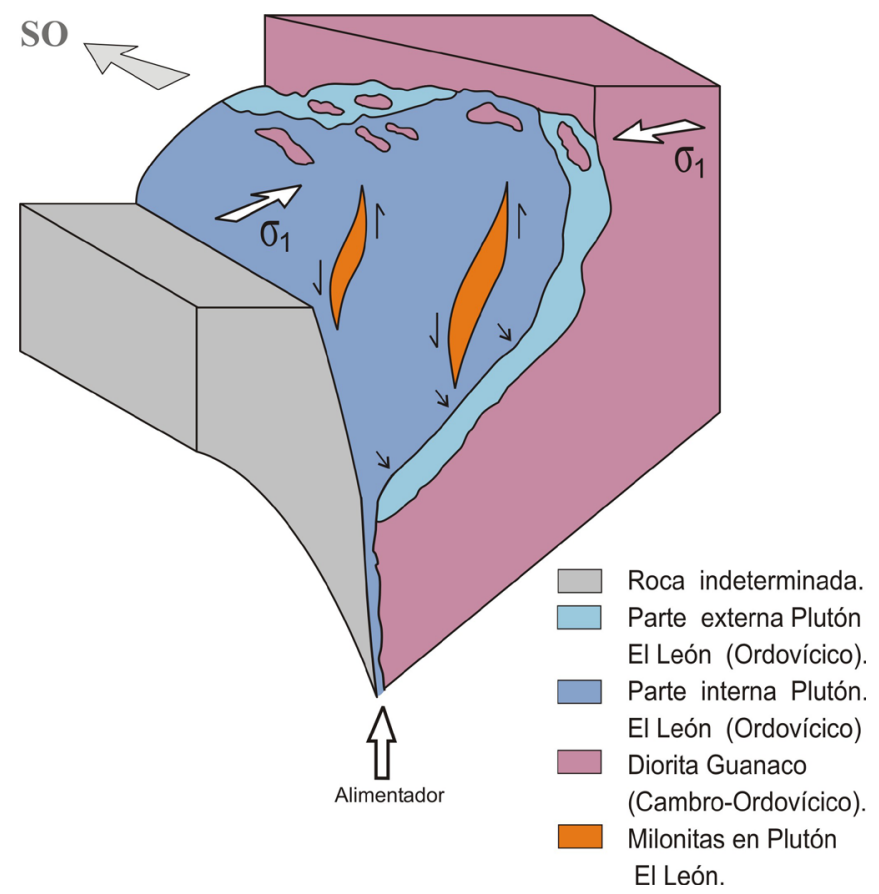

FIG. 15. Modelo de emplazamiento de tipo pistón descendente propuesto para el emplazamiento del Plutón El León (basado en Cruden, 1998), de forma tabular. Las flechas dobles en los bordes de las milonitas indican el movimiento normal-sinistral en las milonitas. Las flechas simples indican el movimiento dúctil descendente del piso del plutón. Las flechas blancas horizontales indican la orientación compresiva de sigma 1 durante la Fase tectónica Guandacol.

\section{Agradecimientos}

Se agradece la revisión crítica del manuscrito por parte de J. Skármeta, G. González y W. Vivallo. Asimismo, los autores agradecen la determinación de los bordes metamórficos de zircones en la muestra de Basamento CHU-HN07/12 por parte de S. Meffre, del Laboratorio de Geocronología de la Universidad de Tasmania, Australia. La mayor parte de los dibujos fueron hechos por L. Jofré.

\section{Referencias}

Altenberger, U.; Wilhelm, S. 2000. Ductile deformation of K-feldspar in dry eclogite facies shear zones in the Bergen Arcs, Norway. Tectonophysics 320 (2): 107-121. doi: 10.1016/S0040-1951(00)00048-2.

Arbaret, L.; Fernández, A.; Jezek, J.; Ildefonse, B. 2000. Analogue and numerical modeling of shape fabrics: application to strain and flow determination in magmas. Earth and Environmental Science Transactions of The Royal Society of Edinburg 91 (1-2): 97-109.

Blenkinsop, T. 2002. Magmatic and Sub-magmatic Deformation. In Deformation Microstructures and Mechanisms in Minerals and Rocks. Springer: 59-64. Dordrecht.
Blumenfeld, P.; Mainprice, D.; Bouchez, J.L. 1986. C- slip in quartz from subsolidus deformed granite. Tectonophysics 127 (1-2): 97-115. doi: 10.1016/0040-1951(86)90081-8.

Cruden, A.R. 1998. On the emplacement of tabular granites. Journal of the Geological Society of London 155 (5): 853-862. doi:10.1144/gsjgs.155.5.0853.

Fazio, E.; Fiannacca, P.; Russo, D.; Cirrincione, R. 2020. Submagmatic to Solid-State Deformation Microstructures Recorded in Cooling Granitoids during Exhumation of Late-Variscan Crust in North-Eastern Sicily. Geosciences 10 (311): 1-29. doi: 10.3390/geosciences 10080311.

Gapais, D. 1989. Shear structures within deformed granites: Mechanical and thermal indicators. Geology 17 (12): 1144-1147.

Hirth, G.; Tullis, J. 1992. Dislocation creep regimes in quartz aggregates. Journal of Structural Geology 14 (2): 145-159. doi: 10.1016/0191-8141(92)90053-Y.

Jessell, M.W. 1987. Grain-boundary migration microstructures in a naturally deformed quartzite. Journal of Structural Geology 9 (8): 1007-1014. doi: 10.1016/0191-8141(87)90008-3.

Kruhl, J.H. 1996. Prism- and basal-plane parallel subgrain boundaries in quartz: A microstructural 
geothermobarometer. Journal of Metamorphic Geology 14 (5): 581-589. doi: 10.1046/j.1525-1314.1996.00413.x.

Michea, H. 2014. Análisis cinemático y dinámico de la Falla Tucúcaro, Cordón de Lila. Memoria de título (Inédito), Universidad Católica del Norte, Departamento de Ciencias Geológicas: 57 p.

Nicolas, A. 1992. Kinematics in Magmatic Rocks with Special Reference to Gabbros. Journal of Petrology 33 (4): 891-915. doi: 10.1093/petrology/33.4.891.

Niemeyer, H. 2020a. Geoquímica de las rocas plutónicas del batolito cambro-ordovícico del Cordón de Lila y de la Sierra de Almeida, Región de Antofagasta, Chile. Andean Geology 47 (3): 628-640. doi: 10.5027/andgeoV47n3-3305.

Niemeyer, H. 2020b. El Basamento metamórfico del Cordón de Lila, Región de Antofagasta, Chile. Revista de la Asociación Geológica Argentina 77 (4): 505-511.

Niemeyer, H.; Meffre, S.; Guerrero, R. 2014. Zircon U-Pb geochronology of granitic rocks of the Cordón de Lila and Sierra de Almeida ranges, northern Chile: 30 m.y. of Ordovician plutonism on the western border of Gondwana. Journal of South American Earth Sciences 56: 228-241. doi: 10.1016/j.jsames.2014.09.011.

Niemeyer, H.; Sanhueza, M. 2016. La Orogénesis Famatiniana en la Puna occidental de Argentina y en el Norte de Chile. Revista de la Asociación Geológica Argentina 73 (3): 341-347.

Pankhurst, R.J.; Hervé, F.; Fanning, C.M.; Calderón, M.; Niemeyer, H.; Griem-Klee, S.; Soto, F. 2016. The pre- Mesozoic rocks of northern Chile: $\mathrm{U}-\mathrm{Pb}$ ages, and $\mathrm{Hf}$ and $\mathrm{O}$ isotopes. Earth-Science Reviews 152: $88-105$.

Paterson, S.R.; Vernon, R.H.; Tobisch, O.T. 1989. A review of criteria for the identification of magmatic and tectonic foliations in granitoids. Journal of Structural Geology 11 (3): 349-363. doi: 10.1016/0191-8141(89)90074-6.

Paterson, S.R.; Fowler, T.K.; Schmidt, K.L.; Yoshinobu, A.S.; Yuan, E.S.; Miller, R.B. 1998. Interpreting magmatic fabric patterns in plutons. Lithos 44: 53-82.

Passchier, C.W.; Trouw, R.A.J. 2005. Microtectonics. Springer: 371 p. Berlin.

Pennacchioni, G.; Zucchi, E. 2013. High temperature fracturing and ductile deformation during cooling of a pluton. The Lake Edison granodiorite (Sierra Nevada batholith, California). Journal of Structural Geology 50: 54-81. doi: 10.1016/j.jsg.2012.06.001.

Poirier, J.P. 1985. Creep of crystals: high-temperature deformation processes in metals, ceramics and minerals. Cambridge University Press: 276 p. Cambridge.

Pryer, L.L.; Robin, P.Y.F.; Lloyd, G.E. 1995. A SEM electron channelling study of flame perthite from the Killarney Granite, Southwestern Grenville Front, Ontario. The Canadian Mineralogist 33 (2): 333-347.

Salfity, J.A.; Malanca, M.E.; Brandán, C.R.; Monaldi, C.R.; Moya, M.C. 1984. La Fase Guandacol (Ordovícico) en el Norte de la Argentina. In Congreso Geológico Argentino, No. 9, Actas 1: 555-567. Bariloche.

Stipp, M.; Stünitz, H.; Heilbronner, R.; Schmid, S.M. 2002. The eastern Tonale fault zone: a "natural laboratory" for crystal plastic deformation of quartz over a temperature range from 250 to $700{ }^{\circ} \mathrm{C}$. Journal of Structural Geology 24: 1861-1884.

Streckeisen, A. 1974. Rocas plutónicas. Clasificación y nomenclatura recomendada por la Unión Internacional de Ciencias Geológicas (I.U.G.S.). Subcomisión en sistemática de rocas ígneas. Traducido al Castellano de Neues Jahrbuch für Mineralogie, Abhandlungen. Instituto de Investigaciones Geológicas 107: 144-240. Santiago.

Valencia, E. 2014. Caracterización geológico-estructural del borde Norte del Plutón Pingo-Pingo y su aureola de contacto, Cordón de Lila, Región de Antofagasta. Memoria de Título (Inédito), Departamento de Ciencias Geológicas, Universidad Católica del Norte: 135 p.

Zák, J.; Holub, F.V.; Kachlík, V. 2006. Magmatic stoping as an important emplacement mechanism of Variscan plutons: evidence from roof pendants in the Central Bohemian Plutonic Complex (Bohemian Massif). International Journal of Earth Sciences 95: 771-789. doi: 10.1007/s00531-006-0076-8.

Zimmermann, U.; Niemeyer, H.; Meffre, S. 2010. Revealing the continental margin of Gondwana: The Ordovician arc of the Cordón de Lila (northern Chile). International Journal of Earth Sciences (Geologische Rundschau) 99 (Suplement 1): 39-56.

Manuscrito recibido: Julio 3, 2020; revisado/aceptado: Febrero 05, 2021; disponible en línea: Mayo 31, 2021. 